\title{
Sarcoma del estroma endometrial como masa retroperitoneal
}

\section{Endometrial Stroma Sarcoma as a Retroperitoneal Mass}

\author{
María Alejandra Maestro Durán ${ }^{1}$ Lucía Alvarez Devesa ${ }^{1} \quad$ Daniel Fraga Manteiga ${ }^{1}$ \\ ${ }^{1}$ Departamento de Radiología, Complejo Hospitalario Universitario \\ de A Coruña, Coruña, España \\ Address for correspondence María Alejandra Maestro Durán, MD, As \\ Xubias 84, A Coruña, 15006, España \\ (e-mail: maria.alejandra.maestro.duran@sergas.es).
}

Rev Argent Radiol 2021;85:24-26.

Estimado editores,

Los sarcomas del estroma endometrial son tumores poco frecuentes, que suponen el $20 \%$ de los sarcomas uterinos y menos del $1 \%$ de todos los tumores malignos del útero. Su aparición fuera del útero es muy rara. Frecuentemente son sintomáticos, apareciendo metrorragia en un $90 \%$ de los casos. La Organización Mundial de la Salud (OMS) ${ }^{1}$ reconoce dos subtipos según su grado histológico, con diferente comportamiento inmunohistoquímico y clínico.

Tienen un pronóstico variable y suelen ser detectados en estadios avanzados, mientras que los de bajo grado siguen un curso y crecimiento indolente. ${ }^{2}$

Mostramos el caso de una mujer de 65 años, asintomática, con ligera alteración de la creatinina sérica como hallazgo casual en una analítica de rutina, remitida al Servicio de Radiodiagnóstico para una ecografía abdominal de forma programada por una leve elevación de la creatinina sérica.

Al realizar el estudio, se observa un riñón derecho con dilatación pielocalicial y adelgazamiento cortical. El uréter proximal se encuentra dilatado hasta una masa retroperitoneal de gran tamaño y vascularizada, anterior a los cuerpos vertebrales y a la derecha de la aorta (-Fig. 1).

Se completó con tomografía computada (TC) tras administración de contraste intravenoso y oral en fase venosa, identificándose una gran masa retroperitoneal derecha, de $19 \times 9,3 \times 8,3 \mathrm{~cm}$ aproximadamente. Engloba al uréter y vena cava inferior hasta su bifurcación, a la vena iliaca común, externa e interna derechas, en contacto con la aorta abdominal (-Fig. 2). Tiene contornos polilobulados y atenuación heterogénea con áreas hipodensas centrales, sin grasa macroscópica ni

received

October 29, 2019

accepted

August 4, 2020

published online

December 22, 2020 calcificaciones y moderado realce tras la administración de contraste intravenoso. Está en íntimo contacto con el músculo psoas, los cuerpos vertebrales derechos (L3-S1) y la cúpula uterina, en el que se observan leiomiomas, sin signos de infiltración de los mismos ni metástasis.

Se realizó una biopsia guiada por ecografía por parte de la Sección de Radiología Vascular e Intervencionista, sin complicaciones inmediatas. Horas después, la paciente entró en parada cardiorrespiratoria y falleció.

Para filiar la masa retroperitoneal y confirmar la causa de la muerte, se realizó autopsia clínica, tras el consentimiento familiar, que determinó que la lesión era un sarcoma del estroma endometrial y confirmó como causa del exitus un tromboembolismo pulmonar agudo masivo.

Durante el estudio anatomopatológico de la masa (-Fig. 3), la pieza macroscópica reveló que la lesión también afectaba a las venas uterinas derechas. La inmunohistoquímica fue decisiva para su diagnóstico. Fueron positivos marcadores característicos de este tipo de tumores como el CD10 y receptores de estrógenos y progesterona dado su origen uterino.

Los tumores del estroma endometrial no presentan patogenia clara con posibles factores predisponentes como la obesidad, diabetes, menarquia temprana y tamoxifeno. Son tumores poco frecuentes, en los que se ha descrito una translocación específica $t(7,17) .^{3}$ Más de la mitad aparecen en mujeres premenopaúsicas, sobre todo aquellos de bajo grado histológico. ${ }^{4}$ Aunque los sarcomas uterinos se describen como tumores agresivos, el sarcoma del estroma endometrial tiene un bajo porcentaje de infiltración según la
(C) 2020. Asociación Civil Sociedad Argentina de Radiología and Federacion Argentina de Asociaciones de Radiología, Diagnóstico por Imágenes y Terapia Radiante. All rights reserved.

This is an open access article published by Thieme under the terms of the Creative Commons Attribution-NonDerivative-NonCommercial-License, permitting copying and reproduction so long as the original work is given appropriate credit. Contents may not be used for commercial purposes, or adapted, remixed, transformed or built upon. (https://creativecommons.org/ licenses/by-nc-nd/4.0/)

Thieme Revinter Publicações Ltda., Rua do Matoso 170, Rio de Janeiro, RJ, CEP 20270-135, Brazil 

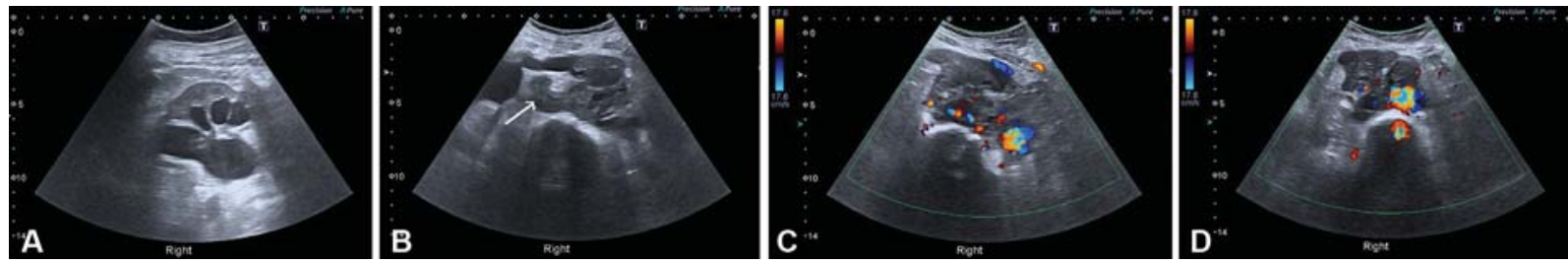

Fig. 1 Imágenes del estudio ecográfico en modo B (A y B) y con Doppler color (Cy D), en las que se observa el adelgazamiento de la cortical renal derecha con dilatación del sistema pielocalicial y uréter proximal hasta una masa retroperitoneal (flecha blanca en B), con vascularización detectable a la derecha de la aorta.
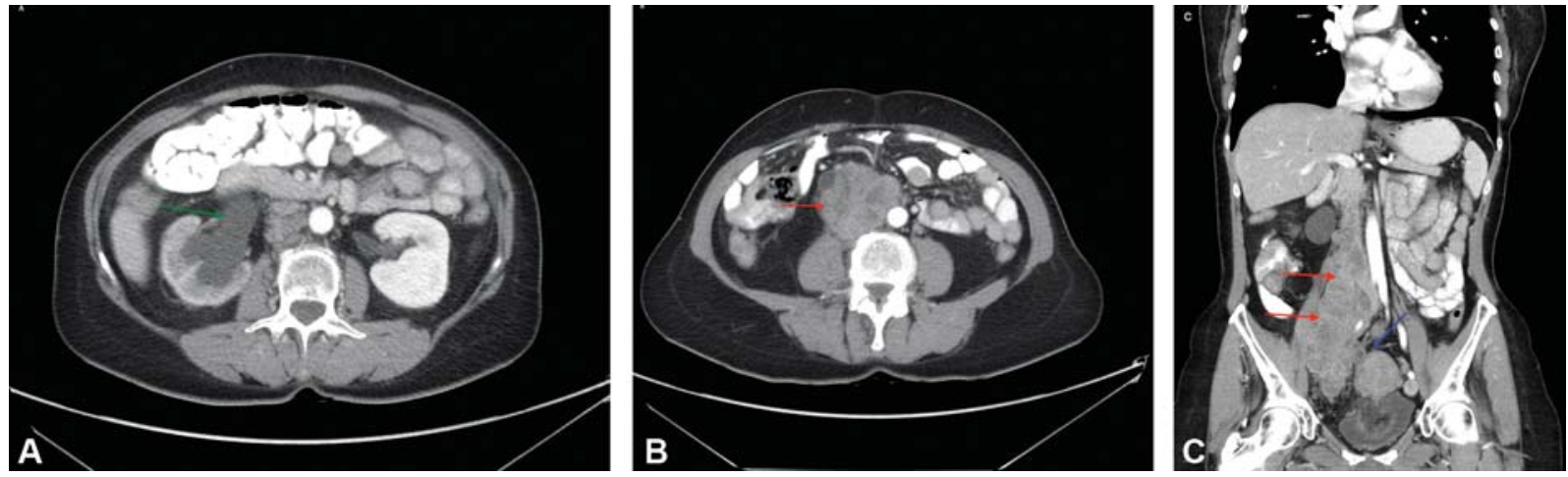

Fig. 2 Cortes axiales (A y B) y coronal (C) más representativos del estudio TC, donde se visualiza la dilatación de la vía urinaria derecha (flecha verde) secundaria a una gran masa retroperitoneal (flechas rojas), polilobulada y heterogénea, que engloba al uréter y la vena cava inferior extendiéndose más allá de la bifurcación iliaca y contacta con la cúpula uterina (flecha azul).
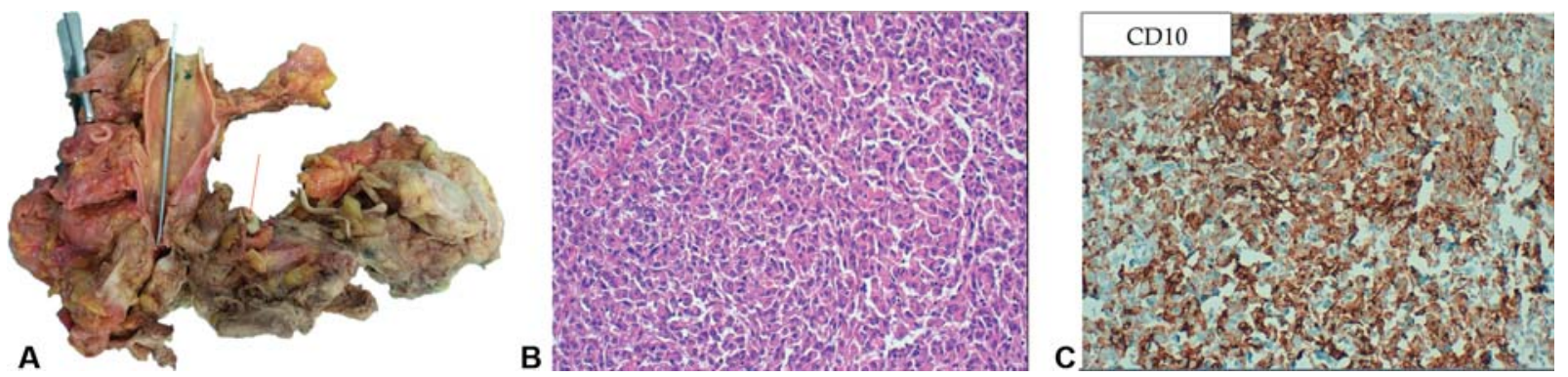

Fig. 3 Aspecto macroscópico y microscópico del tumor. En la pieza macroscópica (A) se observa el crecimiento de la lesión desde las venas uterinas derechas (flecha roja en A). En B se observa aspecto microscópico de la lesión tras la tinción de hematoxilina-eosina y en $\mathbf{C}$ se evidencia positividad del marcador inmunohistoquímico CD10 en la muestra, específico para los tumores del estroma endometrial.

literatura, algo que contrasta con nuestro caso de bajo grado histológico. ${ }^{4}$

La sintomatología es similar a la de otras neoplasias de origen uterino, como metrorragias (en el $90 \%$ de los casos) y dolor pélvico o abdominal, algo que nunca presentó la paciente.

El diagnóstico prequirúrgico es poco frecuente, confundiéndose con otras neoplasias benignas y solo se conocen tras el estudio anatomopatológico de la pieza postquirúrgica tras histerectomía. ${ }^{5}$ El diagnóstico diferencial de este tipo tumoral normalmente incluye neoplasias intrauterinas, como el leiomioma u otras de bajo grado como el adenosarcoma mulleriano.

En nuestro caso, por eso sorprendente y diferente, al tratarse de una masa retroperitoneal, se trató en el diagnóstico diferencial como un tumor retroperitoneal primario. ${ }^{5}$ El epicentro de la masa parece contiguo a la vena cava inferior, siendo el leiomiosarcoma de cava la primera opción. Dado el contacto íntimo que parecía tener con la cavidad uterina, un origen uterino fue la segunda posibilidad.

El estudio mediante inmunohistoquímica es clave, ya que tienen un marcador específico celular, el CD10, que permite diferenciarlas de otros tumores como el leiomioma. De manera frecuente, también es positivo para los receptores de los estrógenos y progesterona.

Su pronóstico está marcado por la extensión extrauterina al diagnóstico, precisando un abordaje multidisciplinar. ${ }^{1}$ El tratamiento inicial debe ser quirúrgico, ya que la eficacia del tratamiento adyuvante no ha sido demostrada, sólo usado si existen recurrencias. Las tasas de supervivencia varían según el estadio en el momento del diagnóstico, siendo muy bajas en los estadios III o IV, del $11 \%$ a los 5 años. ${ }^{2}$ 
26 Sarcoma del estroma endometrial como masa retroperitoneal Maestro Durán y col.

Los sarcomas del estroma endometrial son un grupo de tumores cuya aparición fuera del útero es aún más rara, pero consideramos importante conocerlos para tenerlos en cuenta en el diagnóstico diferencial, no solo de las neoplasias confinadas al útero sino también ante una masa retroperitoneal de origen incierto, como es el caso que mostramos.

Protección de personas y animales

Los autores declaran que para esta investigación, no se han realizado experimentos en seres humanos ni en animales.

\section{Confidencialidad de los datos}

Los autores declaran que han seguido los protocolos de su centro de trabajo sobre la publicación de datos de pacientes.

Derecho a la privacidad y consentimiento informado Los autores declaran que en este artículo no aparecen datos de pacientes.
Conflicto de intereses

Los autores del trabajo declaran no tener ningún conflicto de intereses.

\section{Bibliografía}

1 Tavassoli FA, Devilee P. WHO Classification of Pathology and genetics of tumours of the breast and female genital organs. J Clin Pathol. 2005;58(06):671-672

2 Puliyath G, Nair MK. Endometrial stromal sarcoma: A review of the literature. Indian J Med Paediatr Oncol. 2012;33 (01):1-6

3 Micci F, Panagopoulos I, Bjerkehagen B, Heim S. Consistent rearrangement of chromosomal band $6 \mathrm{p} 21$ with generation of fusion genes JAZF1/PHF1 and EPC1/PHF1 in endometrial stromal sarcoma. Cancer Res. 2006;66(01):107-112

4 Lee CH, Nucci MR. Endometrial stromal sarcoma-the new genetic paradigm. Histopathology. 2015;67(01):1-19

5 Brennan C, Kajal D, Khalili K, Ghai S. Solid malignant retroperitoneal masses-a pictorial review. Insights Imaging. 2014;5(01):53-65 